\title{
Groundwater recharge through winter flooding of rice areas
}

\author{
Arianna Facchi1 ${ }^{1 *}$, Camilla Negri ${ }^{1}$, Michele Rienzner ${ }^{1}$, Enrico Chiaradia $^{1}$, and \\ Marco Romani ${ }^{2}$ \\ ${ }^{1}$ Dipartimento di Scienze Agrarie e Ambientali - Produzione, Territorio, Agroenergia, Università \\ degli Studi di Milano (DiSAA-UNIMI), via Celoria 2, 20133 Milano \\ arianna.facchi@unimi.it \\ ${ }^{2}$ Centro Ricerche Riso, Ente Nazionale Risi (CRR-ENR), strada per Cerretto 4, Castello \\ d'Agogna, Pavia
}

\begin{abstract}
Starting from October 2017, the hydrological balance of a 36 hectares' rice area located in Lomellina (PV), where the practice of winter flooding has been adopted since 2004, has been under investigation. Flow meters were installed on the irrigation and drainage channels, piezometers were positioned inside and outside the study area, and a soil survey was performed. A conceptual hydrological model simulating the water balance at the paddy field scale was developed and calibrated. Main results show that: (a) irrigation efficiency of the pilot area during the first summer season is well in line with those found for other paddy areas in the region; (b) higher percolation rates are observed in wintertime compared to summer season; (c) despite the higher percolation, groundwater level reached in winter season is slightly lower than in summer, and the groundwater depletion after the end of the flooding period is faster compared to that observed after the summer flooding; (d) to maintain higher groundwater levels at the beginning of the cropping season, which would increase irrigation efficiency, winter flooding should be maintained longer over time and involve larger paddy areas.
\end{abstract}

Keywords: winter flooding, groundwater recharge, hydrological model, irrigation efficiency, paddy

\section{Introduction}

Recent research suggests that groundwater overdraft can be mitigated by diverting flood waters onto agricultural lands for direct groundwater recharge (Bachand et al., 2016). This technique is often called Ag-MAR (where Ag is for Agricultural and MAR for Managed Aquifer Recharge) and is usually carried out during wintertime, when water is abundant since it is not used for irrigation (Niswonger et al., 2017). Recently, Ag-MAR has been adopted in a few agricultural areas of the USA, particularly in California. In Europe, the implementation of winter flooding (WF) of rice paddies has been promoted since the late nineties as an environmentally friendly technique to de- 
grade straw residue as well as to provide foraging habitats to winter waterfowl and other wildlife. However, in Northern Italy it was introduced as an agro-environmental measure in the EU-RDP 2014-2020 and thus it has been adopted only recently. If a few studies in recent years have focused on biodiversity and agronomic effects of winter flooding, no studies have investigated its impacts on the hydrological balance of rice areas in terms of both groundwater recharge and possible increase of irrigation efficiency during summertime (as a consequence of a higher soil water content and/or higher groundwater level at seeding time).

\section{Materials and methods}

\subsection{Study area}

The study area is located in Zeme (PV, Italy), about $50 \mathrm{~km}$ south-west of the city of Milan, in the middle of the main Italian rice growing area, between Lombardy and Piedmont. The study area is cropped with rice and it extends for about 36 hectares (9 adjacent paddies). Winter flooding has been practiced since 2004-2008 in 5 fields (old WF fields), and it was extended to the rest of the paddies in 2016 (new WF fields) with the introduction of EU-RDP 2014-2020. Some maize fields (for a total of 6 ha) are also located within the study area. The farm is surrounded by other rice farms most of which do not practice winter submersion. A soil survey was carried out to characterize the area. The information garnered with the survey was used to describe the soil distribution and the average depth of impervious layer (low conductivity layer or LCL hereafter), often being the hardpan. A rather high variability amongst and within the fields, but a fairly even depth and thickness of the LCL (horizon between $30-50 \mathrm{~cm}$ depth) were observed. Given the topography of the study area, in which the altitude decreases from west to east, it was decided, with respect to the groundwater depth, to divide the area in two main blocks. The first block (high WF fields, 4 paddies) is comprised of all the fields surrounding the Z1 piezometer, having an average altitude of $105 \mathrm{~m}$ a.s.l. The second block (low WF fields, 5 paddies) is comprised of all the fields surrounding the Z2 piezometer, having an average altitude of $104 \mathrm{~m}$ a.s.l. (Z1 and Z2 are shown in Fig. 1).

\subsection{Irrigation management}

Data related to the irrigation management during winter and summertime were provided by the farmer. In particular, winter water management consists of irrigating all rice fields from October to the end of January, keeping ponding water at about $10-25 \mathrm{~cm}$ above the soil surface. While winter management is uniform all over the farm (all fields are submerged more or less at the same time), summer management follows either traditional flooding or dry seeding and delayed flooding practices. In the 
farm, traditional flooding sowing is followed by a dry period for enhancing root development (1 month), a second water flooding (1 month), a second drainage period followed by flooded conditions until the final drying (about 3 weeks before harvest). In the case of dry seeding and delayed flooding, the first submersion is conducted about one month after sowing and is followed by a drying period and a second flooding lasting until the final drying. Maize fields were border irrigated two times during the cropping season 2018 by means of a pump coupled with a tractor taking water from the ditch supplying the rice fields. The amount of water diverted to maize fields was computed (by measuring motor rpm and irrigation duration, and by applying the relationship provided by the pump manufacturer). The discharge was then removed from the water inputs, obtaining water inflow to the paddies. Lastly, a single field ('Zan 16-18'), was managed differently during the first winter, being kept flooded from October 2017 to April 2018.

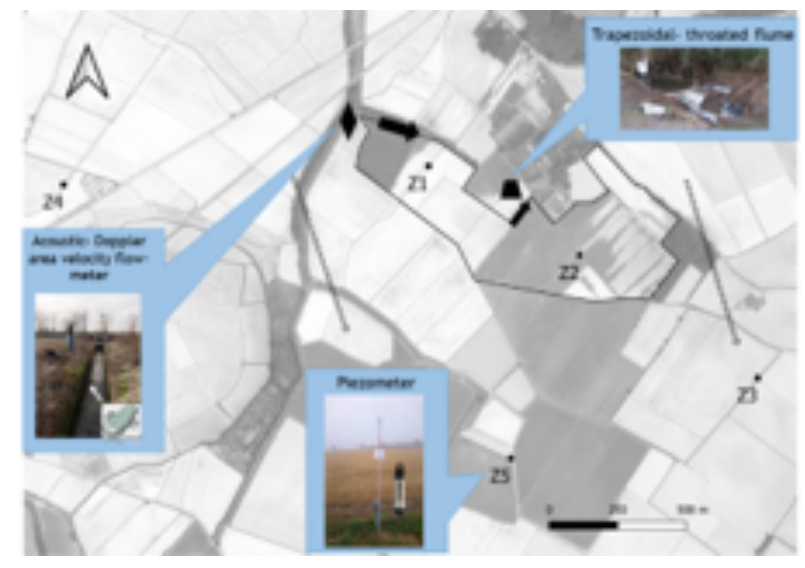

Fig. 1 Study area and position of the monitoring devices. Piezometers (from Z1 to Z5) are shown by black dots, the acoustic-Doppler inflow-meter by a diamond, and outflow flumes by a trapezoid. The main groundwater flow direction is shown by dashed arrows, while surface water flow direction by black arrows.

\subsection{Surface water inflow, outflow and groundwater levels}

The surface water inflow discharge in the irrigation channel providing water to the nine field of the study area was measured using an acoustic-Doppler area-velocity flow meter (SonTek-IQ Standard), while two trapezoidal long-throated flumes were used in combination with pressure transducers to measure the surface water outflow discharge in the drainage channel collecting tailwater. The flumes were self-made, and designed to fit a maximum discharge of $120 \mathrm{l} \mathrm{s}^{-1}$ each. Flow rate curves were estimated using the WinFlume software (U.S.B.R., USA), as illustrated in Chiaradia et al. (2015). Groundwater levels were monitored using five piezometers: two located inside and three outside the area. Wells were made of 4.5 meters PVC pipes (the lower $1.5 \mathrm{~m}$ were windowed) installed into holes drilled with a manual auger, pressure transducers 
were positioned inside the wells in order to continuously measure water levels. Fig. 1 shows the devices installed. The study site was instrumented in the October 2017; thus, data of two winter (2017-2018 and 2018-2019) and one summer (2018) seasons are available.

\subsection{Semi-distributed conceptual model: set up and calibration}

Since water flow measurements were taken at the inlet irrigation channel and outlet drainage channel, respectively delivering irrigation water and collecting tailwater from the nine fields, discharge inflow and outflow of each paddy field are actually unknown.

A semi-distributed model was set up so to gain a deeper knowledge of the system's processes, providing an estimation of all the water fluxes and storages at the field scale, to double-check measured fluxes and irrigation scheduling reported by the farmer in the farm-diary, as well as to investigate the relevance of groundwater levels, thickness of the ponding water above the paddy, and soil properties (i.e., saturated hydraulic conductivity of the LCL) on percolation losses. The model was built setting the water amount available for irrigation within the study area as the difference between irrigation inflow (Qin) and outflow (Qout), while the time for the water to travel from the inlet to the outlet of the system, the water storage in the channels and the lateral seepage through the bounds were considered to be negligible. In particular, when the difference between Qin and Qout was positive, the water flux was considered entering the system, and vice-versa if negative. Each of the nine paddy fields was simulated as two tanks in series: the first tank being the top soil $(0-30 \mathrm{~cm}$, above the LCL), the second being the ponding water above the paddy. Equation 1 defines the balance equation for each paddy:

\section{(Eq. 1)}

Where: $t$ is the hourly time index, is the variation in ponding water, is the variation in water storage within the first $0-30 \mathrm{~cm}$ of soil profile, and are the measured irrigation inflow and outflow, is the rain, is the evapotranspiration and is the percolation term of the equation. All the terms of Eq. 1 are expressed in millimetres, with the exception of and $\left(\mathrm{L} \mathrm{s}^{-1}\right)$ and is a conversion factor which accounts for the fields' area. The terms and are considered mutually exclusive: when the soil tank is full (the upper soil is saturated, ), the value of the right hand side of Eq. 1 is allocated only to ; when the water tank is empty () that value in the right hand side of Eq. 1 is allocated only to . The water inflow/outflow ( and ) to/from a single field was considered different from zero only if the corresponding inlet/outlet was open, according to the farm-diary provided by the farmer. For each hour, the total amount of incoming/outcoming water was split among the fields with open inlet/outlet according to their area and ponding water level (computed by the model at the previous time step). Evapotranspiration (), considered as potential when the water content of the shallow soil (0-30) was over the field capacity, was calculated according to the FAO multiplied by a single crop coefficient () (Allen et al., 1998). When the soil was dry, a stress coefficient was taken into ac- 
count according to the FAO-56 method (Allen et al., 1998). During winter flooding, the for ponded water suggested by Allen et al. (1998) was adopted ( = 1.05), while during the agricultural season, rice phenology was estimated from Sentinel-2 (ESA) images. The crop coefficients () for the two irrigation treatments (i.e. wet and dry seeding) were derived from a previous study carried out in the same area (Chiaradia et al., 2015; Cesari de Maria et al., 2017). In presence of ponding water in the field and rice $\mathrm{Kc}$ lower then 1.05, the latter value was adopted. When the soil tank is full (saturated soil), the percolation term () was computed through the Darcy law (following the approach described in Facchi et al., 2018); in case of unsaturated soil the percolation was strongly reduced, and it was set to zero as the soil moisture dropped below the field capacity. For each of the nine paddies, the model simulates: ponding water level (state variable), soil water content (state variable) and percolation (Darcy law). According to Facchi et al., 2018, percolation through the LCL can be computed once the following data are known: depth and thickness of the LCL (measured during the soil survey), ponding water levels (state variable), distance between the groundwater table and the lower side of the LCL (depending on the groundwater level), and the saturated hydraulic conductivity of the LCL (Ks). The groundwater level is measured in the center of two groups of fields (high and low; Fig. 1). However, the average groundwater level for each field was unknown as, especially during the winter, the water table is expected to be subject to border effects while approaching the borders of the submerged area. To account for this, the average groundwater level under the fields in each one of the two blocks was assumed to be the one measured by the piezometers (Z1 or Z2) added to an offset ( $\delta 1$ and $\delta 2$ ) obtained by calibration. With respect to hydraulic conductivities, two Ks values were calibrated: one for the old WF fields, Ksold, and one for the new WF fields, $\mathrm{Ks}_{\text {new }}$. During the calibration for the summer season 2018 it turned out that calibrating the Ks of 'Zan 16-18' (Ks 16-18) was mandatory for achieving satisfactory results. Calibration procedures were carried out through the MATLAB Global Calibration Toolbox using an objective function based on the difference between simulated and expected levels of ponding water in the paddy fields. Such expected levels are varying throughout the year, according to the phenological phases of rice and to what reported by the farmer. Table 1 summarizes water fluxes and storages considered in the model, highlighting measured and simulated ones. 
Table 1 Water fluxes and storages considered by the semi-distributed conceptual model

\begin{tabular}{ll}
\hline Dataset & Type of data \\
\hline Rain, Qin & Measured data \\
Qout & Measured data \\
Groundwater table depth & Measured data \\
$\begin{array}{l}\text { Depth of ponding water / } \\
\text { soil desaturation }\end{array}$ & Simulated by the model \\
Summer evapotranspiration & $\begin{array}{l}\text { Simulated by the FAO-PM equation, with crop coefficient } \\
\text { (Kc) based on a previous study in the same rice area }\end{array}$ \\
Winter evaporation & $\begin{array}{l}\text { Simulated by the FAO-PM equation with a constant crop } \\
\text { coefficient for water (Kc = 1.05) }\end{array}$ \\
Groundwater recharge & $\begin{array}{l}\text { Simulated by using the Darcy's law under flooded condi- } \\
\text { tions (Ks of the LCL is the calibration parameter), as in }\end{array}$ \\
\hline
\end{tabular}

\section{Results and discussion}

\subsection{Hydrological balance}

Table 2 summarizes the main results concerning the quantification of water fluxes and storages during winter and summer seasons in the study area. In winter the balance is computed from the start of the submersion to the drying of the fields (11-Oct-2017 to 25-Jan-2018; 14-Oct-2018 to 24-Jan-2019). In the summer period the balance was computed from 11-Apr-2018 (when the first field was water-seeded) to the 19Aug-2018 (harvest occurred on 21-Sep-2018 on average), while the results shown in parenthesis refer only to the time period in which $100 \%$ of the fields were flooded (21May-2018 to 19-Aug-2018). The results show that wintertime percolation rates are two fold those observed during the summer season. This could be due to higher ponding water levels within the fields, lower evaporative processes, lower groundwater levels and, also, by higher paddy soil hydraulic conductivities in wintertime (discussed in Section 3.2). 
Table 2 Results of the hydrological balance for the study area

\begin{tabular}{lccc}
\hline Variables & $\begin{array}{c}\text { First } \\
\text { winter }\end{array}$ & $\begin{array}{c}\text { First } \\
\text { summer }\end{array}$ & $\begin{array}{c}\text { Second } \\
\text { winter }\end{array}$ \\
\hline Length of flooding (days) & 106 & $130(90)$ & 102 \\
Rain $(\mathrm{mm})$ & 117.0 & $\begin{array}{c}260.4 \\
(114.4)\end{array}$ & 179.8 \\
Qin-Qout $(\mathrm{mm})$ & 4185.6 & $2388(2030)$ & 4141.4 \\
Average groundwater depth Z1 (cm) & 81 & $128(76)$ & 124 \\
Average groundwater depth Z2 (cm) & 147 & $139(101)$ & 158 \\
Total storage variation $(\Delta \mathrm{Sw}+\Delta \mathrm{Ss})(\mathrm{mm})$ & 149.6 & $29.6(17.7)$ & 63.2 \\
Average ponding water depth $(\mathrm{cm})$ & 13.9 & $(12.5)$ & 14.5 \\
ETc (mm) & 52.4 & 607.0 & 67.6 \\
ETc (mm)* & - & 712.6 & - \\
Percolation (mm) & 4100 & $2009(1624)$ & 4190 \\
Percolation rate (mm day-1) & 38.5 & $15.4(17.9)$ & 40.5 \\
Percolation efficiency $(\%):$ Percolation/ & 95.3 & $75.8(75.7)$ & 96.9 \\
(Qin - Qout + Rain) & 1.21 & 26.4 & 1.56 \\
WUE (\%): ET/(Qin - Qout + Rain $)^{*}$ & & & \\
\hline
\end{tabular}

* computed on the entire season (from seeding to harvest) in the case of summertime

\subsection{Results of calibration}

The calibration process was carried out independently on the first winter and first summer. The second winter was then used to verify the calibration of the first winter. Table 3 shows calibration results. Parameters obtained for the first winter, when used in the summer of 2018, produced ponding water levels rarely different from zero, while the summer parameters produced ponded water levels far above the physical limits of the system (more than $25 \mathrm{~cm}$, which is the height of the levees). This difference is underlined by the calibrated Ks values, which halve in summer with respect to wintertime. Moreover, this is also confirmed by the percolation rate, which is found to be about $40 \mathrm{~cm} \mathrm{~d}^{-1}$ in wintertime and about $20 \mathrm{~cm} \mathrm{~d}^{-1}$ in summer, showing a difference that cannot be justified only on the basis of the difference in water ponding level and groundwater table depth values in the two seasons. Furthermore, old WF fields show calibrated Ks values lower than those found for new WF fields (on average about $60 \%$, 
both in winter and summer times). Summer Ks value for the field 'Zan 16-18' is below that for old WF fields, probably due to the long submersion time.

Table 3 Results of model calibration, including Ks $\left(\mathrm{cm} \mathrm{day}^{-1}\right)$ and offsets $(\mathrm{cm})$

\begin{tabular}{lccccc}
\hline & $\begin{array}{c}\text { Ks new } \\
\left(\mathrm{cm} \mathrm{d}^{-1}\right)\end{array}$ & $\begin{array}{c}\text { Ks old } \\
\left(\mathrm{cm} \mathrm{d}^{-1}\right)\end{array}$ & $\begin{array}{c}\text { Ks 16-18 } \\
\left(\mathrm{cm} \mathrm{d}^{-1}\right)\end{array}$ & $\begin{array}{c}\text { Offset High } \\
(\mathrm{cm})\end{array}$ & $\begin{array}{c}\text { Offset Low } \\
(\mathrm{cm})\end{array}$ \\
\hline Winter 2017-18 & 0.90 & 0.49 & 0.49 & -28 & 82 \\
Summer 2018 & 0.45 & 0.29 & 0.08 & 0 & 0 \\
\hline
\end{tabular}

With respect to calibrated offsets, summer offsets equal to zero are explained by the fact that in the summertime the farm is surrounded by flooded paddies, hence the groundwater table is not subject to border effects. On the contrary, in wintertime the groundwater table depth below the fields tends to be lower than the one measured in Z1 in the topographically higher block of fields (negative offset), and higher than in $\mathrm{Z} 2$ in the case of lower fields. Parameters calibrated for the winter 2017-2018 were used for the following winter (2018-2019; validation period) producing very good results, as ponding water levels in the fields were well in accordance with data reported in the farm-diary.

Data that is being collected in the 2019 summer season will be indispensable for obtaining more information to better explain the highlighted differences between winter and summer flooding periods.

\subsection{Groundwater levels}

Groundwater levels measured during the first 18 months of investigation (October 2017 - March 2019) are illustrated in Fig. 2. Despite the higher percolation rate, the groundwater level reached in the winter season is slightly lower than in the summer, and the groundwater depletion after the end of the flooding period is faster (about 1 month) compared to that observed after the summer flooding (2-2.5 months).
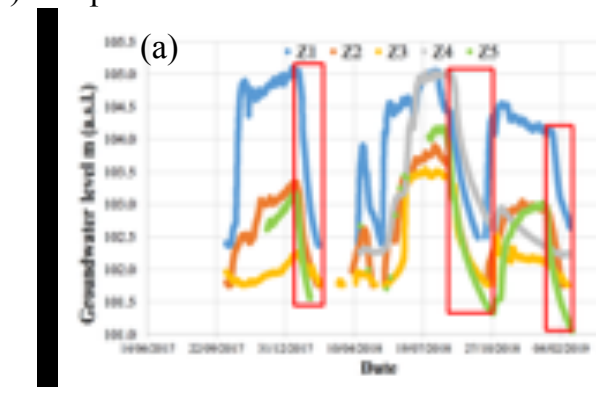

(b)

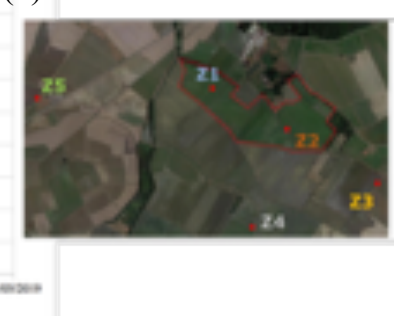

Fig. 2 Groundwater levels ( $m$ a.s.1.) monitored in the study area. Colours in (a) correspond to piezometers in (b). Red boxes highlight the groundwater depletion rates after the flooding periods. 


\section{Conclusions}

The results of the first 18 months of investigation (October 2017 - March 2019) showed that: (a) WF proved to be very effective in recharging the groundwater reservoir, providing percolation rates doubled compared to those observed during summer months because of higher ponding water levels within the fields, lower evaporative processes, lower groundwater levels and probably also to higher soil hydraulic conductivities; (b) despite the higher percolation rate, the groundwater level reached in the winter season is slightly lower than in the summer, and the groundwater depletion after the end of the flooding period is faster (about 1 month) compared to that observed after the summer flooding (2-2.5 months), probably due to the larger and more compacted portion of territory flooded during summer months; (c) as a consequence, to maintain higher groundwater levels at the beginning of the cropping season, which would increase the irrigation efficiency, winter flooding should be maintained longer over time and should involve larger paddy areas.

Acknowledgements The authors wish to acknowledge Regione Lombardia for cofounding the RISTEC project (Operation 1.2.01 - EU-RDP 2014-2020).

\section{References}

Allen, R.G., Pereira, L.S., Raes, D., Smith, M., 1998. FAO Irrigation and drainage paper No. 56. Rome Food Agric. Organ. U. N. 26-40.

Bachand, P.A.M., Roy, S.B., Stern, N., Choperena, J., Cameron, D., Horwath, W.R., 2016. Onfarm flood capture could reduce groundwater overdraft in Kings River Basin. Calif. Agric. 70, 200-207.

Cesari de Maria, S., Bischetti, G. B., Chiaradia, E. A., Facchi, A., Miniotti, E. F., Rienzner, M., Romani, M., Tenni, D., Gandolfi, C., 2017. The role of water management and environmental factors on field irrigation requirements and water productivity of rice. Irrig. Sci. 35, 1126.

Chiaradia, E.A., Facchi, A., Masseroni, D., Ferrari, D., Bischetti, G.B., Gharsallah, O., Cesari de Maria, S., Rienzner, M., Naldi, E., Romani, M., Gandolfi, C., 2015. An integrated, multisensor system for the continuous monitoring of water dynamics in rice fields under different irrigation regimes. Environ. Monit. Assess. 187, 586.

Facchi, A., Rienzner, M., Cesari de Maria, S., Mayer, A., Chiaradia, E.A., Masseroni, D., Silvestri, S., Romani, M., 2018. Exploring scale-effects on water balance components and water use efficiency of toposequence rice fields in Northern Italy. Hydrol. Res. 49, 1711-1723.

Niswonger, R.G., Morway, E.D., Triana, E., Huntington, J.L., 2017. Managed aquifer recharge through off-season irrigation in agricultural regions. Water Resour. Res. 53, 6970-6992. 